University of Texas Rio Grande Valley

ScholarWorks @ UTRGV

Mechanical Engineering Faculty Publications and Presentations

6-18-2018

\title{
Developing and Testing an Electronic Homework System to Improve Student Engagement and Learning in Engineering Thermodynamics
}

\author{
Stephen Crown \\ The University of Texas Rio Grande Valley \\ Constantine Tarawneh \\ The University of Texas Rio Grande Valley \\ Jazmin Ley \\ The University of Texas Rio Grande Valley
}

Follow this and additional works at: https://scholarworks.utrgv.edu/me_fac

Part of the Higher Education Commons, Mechanical Engineering Commons, and the Online and Distance Education Commons

\section{Recommended Citation}

Crown, S. W., \& Tarawneh, C., \& Ley, J. (2018, June), Developing and Testing an Electronic Homework System to Improve Student Engagement and Learning in Engineering Thermodynamics Paper presented at 2018 ASEE Annual Conference \& Exposition , Salt Lake City, Utah. 10.18260/1-2--30303

This Article is brought to you for free and open access by the College of Engineering and Computer Science at ScholarWorks@ UTRGV. It has been accepted for inclusion in Mechanical Engineering Faculty Publications and Presentations by an authorized administrator of ScholarWorks @ UTRGV. For more information, please contact justin.white@utrgv.edu,william.flores01@utrgv.edu. 


\section{Developing and Testing an Electronic Homework System to Improve Student Engagement and Learning in Engineering Thermodynamics}

\section{Dr. Stephen W. Crown, University of Texas, Rio Grande Valley}

Dr. Crown is a professor of mechanical engineering at the University of Texas Rio Grande Valley. He is the director of the Edinburg Texas Pre-Freshman Engineering Program and has served as PI and Co-PI on several large engineering education grants to improve pedagogy and access to online resources that positively impact measurable student learning outcomes.

\section{Prof. Constantine Tarawneh, University of Texas, Rio Grande Valley}

Dr. Tarawneh is a Professor of Mechanical Engineering at the University of Texas Rio Grande Valley (UTRGV) where he worked since 2003. He obtained his MS and Ph.D. degrees from the University of Nebraska-Lincoln (UNL) in 1999 and 2003, respectively. He founded the University Transportation Center for Railway Safety (UTCRS) in 2013 and serves as the Center Director. He also serves as the Associate Dean for Research for the College of Engineering and Computer Science since 2016. His various research and educational activities have resulted in more than \$17 Million in funding from federal, industry, state, and local sources. He has more than thirteen years of experience conducting a variety of railroad research with emphasis on advanced bearing condition monitoring techniques. He received 26 teaching, mentoring, and research awards highlighted by the UT System Regents' Outstanding Teaching Award in 2009. In Fall of 2017, he was appointed as the Louis A. Beecherl, Jr. Endowed Professor in Engineering. To date he has taught 24 different courses in his discipline.

\section{Jazmín Ley, University of Texas, Rio Grande Valley}

Jazmín Ley was born on December 26, 1980 in Reynosa, Tamaulipas, Mexico to Mr. Jose Gabriel Ley and Mrs. Maria del Rosario Ley. Thanks to her college mentor and professor Dr. Hashim Mahdi, she found herself enrolled in the Mechanical Engineering Master's Program. While working on her masters, she became involved in research for the railroad industry under the mentorship of the faculty involved in the Railroad Research Team. She worked as a full-time Research Assistant at what is now known as the Railway Safety Center continuing her work on sensor technology for Amsted Rail and their subsidiaries. After her work with the Railroad Research Team, she worked in Texas State Technical College as Department Chair of the Associate of Science in Engineering Program. She currently works in The University of Texas Rio Grande Valley and teaches introduction to engineering materials and engineering materials laboratory, engineering graphics, dynamics, numerical methods, and engineering vibrations. 


\section{Developing and Testing an Electronic Homework System to Improve Student Engagement and Learning in Engineering Thermodynamics}

An electronic homework delivery system was developed for an advanced undergraduate engineering thermodynamics course due to limitations in available electronic homework systems. A commercially available system was effectively used in the introductory course for simple problems. The complexity of problems in the advanced course made adoption of the same system problematic as students needed feedback in the problem-solving process. A system was devised that delivers individual problems to each student, provides feedback throughout the process, and records results for assessment. The system has helped students become more active in homework assignments in both completing assignments and in doing original work. Over time, students would share general solutions from previous semesters and shortcut a deeper understanding of the problems. A recent addition to the system has been the introduction of problems that are based on fundamental concepts rather than using the right equation to get the correct numerical answer. A successful problem implementation gives students a randomly generated 4-6 state heat engine cycle (from 200 developed cycles) that does not correlate with any cycle in literature. Students are forced to work through the basic steps of evaluating a new process relying on their own understanding without being aided by a Google search or a classmate. The overall impact of the system along with the latest addition to student learning are presented.

\section{Introduction}

Engineering Thermodynamics, along with many other courses in the engineering curriculum, is a problems-based course where the correct application of basic engineering principles to solve specific problems is emphasized. As such, the students are expected to learn much of the required skills by solving numerous problems. The struggle of completing mathematical calculations utilizing engineering concepts provides students a necessary process to gain better understanding of fundamental engineering principles (i.e. first and second law of thermodynamics, property relationships, diffusion law in engineering materials, etc.). As students make assumptions to simplify problems, choose equations and solution methods, break complex problems down into component parts, link component parts together to form solutions for complex engineering systems, and reflect on the results of the analysis and associated design they learn engineering. Throughout this learning process, formative assessment and feedback effectively guides students toward mastery of learning objectives [1], [2]. The engineering instructor learns to identify problems that will provide students with the necessary skills to be successful in their course.

For years, chapter-end problems and solution manuals have provided instructors a helpful tool for assigning and assessing students work as part of this learning process. Over time, students acquire solutions to many of the textbook problems. They, in turn, share these answers with their peers, thus, hindering the learning process. So, authors periodically develop new problem sets to accompany their textbooks. Engineering often involves group work as a basis for a learning experience; however, homework in groups provides an environment where students easily share answers with each other preventing a deeper understanding of fundamental concepts. Technology has added an additional challenge by allowing students to not only share with their immediate peers, but with the entire student body online. 
By implementing an online homework system, an instructor can provide students a unique set of homework problems. As such, the system encourages students to invest in their own homework and allows the engineering learning process to take place via problem solving. Online homework systems are a great benefit to students because they provide immediate feedback and encourage students to be individually involved in their homework [3], [4]. The systems also benefit the instructor by providing formative assessment indicating student progress, and since they are selfgrading, instructors will be afforded more time for other learning interventions.

\section{The Need for an Engineering Homework System in Thermodynamics}

An Electronic Learning Management System (ELMS), offered as a companion with the textbook, was used in the introductory Engineering Thermodynamics course with a large-course section several years prior to the current system. Student and instructor feedback identified a disconnect between content students were struggling with and the content focus of the electronic homework ${ }^{3}$. To address this concern, the instructor began to develop new problems and post them online via Blackboard Learn. As the body of homework problems grew and proved to be more effective for student learning, the opportunity for developing an independent homework system became apparent.

The initial advantage was cost and student familiarity. The homework problems were offered on a ELMS system already maintained by the university, and students no longer needed to pay an additional fee for the homework system. In addition, the system was familiar to students as it was being used in many of their other courses. The principle draw back was that the system was not developed for engineering homework and all the problems needed to be developed by the instructor.

Although the full development of the homework problems took hundreds of hours, the initial implementation delivered on the university supported ELMS was a great success. Following a long history of poor student performance in the course, the changes to the course included optional 3hour weekly recitations in all sections, and the full development and online implementation of all homework assignments (over 300 problems) and online exams in one of the course sections. The positive impact of the recitations on student performance are given in an article published in JAPEE [5].

A significant disparity between student performance in the different course sections was observed for two consecutive semesters. Student performance in the sections using the developed online homework was significantly higher than the section that utilized traditional homework assignments. Consequently, the following semester, the homework system was adopted by all sections for thermodynamics, and student performance rose overall indicating a similar performance by both sections. As such, this change indicated that the effective use of the homework system was a more significant factor to student performance than a change of instructor. In 2013, the material was revised for use with Blackboard Learn, and continues to be used today. The entire homework set has proven to be an effective tool with five different instructors and more than 15 sections over the past few years.

Although the developed electronic homework set for Blackboard is still being utilized, there are 
several challenges facing its use in engineering. One major obstacle with Blackboard is that the system only allows a single answer to be given for a calculated problem. For complex problems requiring several steps, students get frustrated that only the final answer is graded possibly representing over an hour of work. Additionally, revisions to the ELMS system have required hundreds of hours of updates to accommodate changes to format for complex calculated problems used in the thermodynamics homework sets. These drawbacks were not significant enough to dismiss the effectiveness of the student accountability associated with the online homework over the end-of-chapter problems.

\section{Development of a New Engineering Homework System for Thermodynamics}

The significant positive impact of the electronic homework developed for introductory thermodynamics course led to a serious consideration for a similar implementation in the advanced engineering thermodynamics class. The complexity of the problems required that multi-step problems would have the same answers for all students if developed in Blackboard Learn. Although the student feedback was positive for the current ELMS, the use of an electronic system that had the same answers for all students would most likely be abused. To address this concern, various meetings with representatives from Blackboard were scheduled, and though their help showed promise, it never led to a functional solution. Instead, an independent ELMS system was developed by the primary author that particularly focused on the requirements needed for engineering homework problems.

The new system would assign unique problem parameters for each student, and grant access to those given values through all steps of a multistep problem. Many of the homework problems developed for the Thermodynamics II course have over twenty answered steps that give students feedback throughout a complex one- to two-hour problem. The individualized problem parameters ensure that each student is engaged in the homework if they are to receive credit. The impact of the new homework system is shown in Figure 1. The overall performance on midterm exams was the highest ever observed following implementation of the online homework system. Overall, homework grades were basically unchanged, but now better represented individual student work was reflected by a significant increase in exam grades.

\section{Impact of New ELMS on Thermodynamics II Grades}

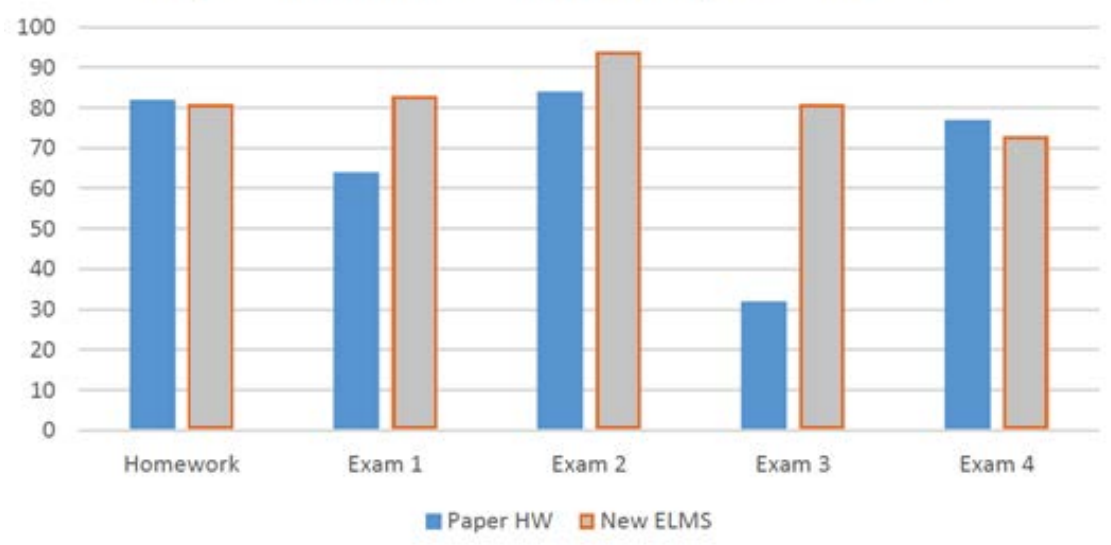

Figure 1:Comparison of traditional homework with new ELMS developed by the author 
The new ELMS system has been used effectively in the course for several years with consistent results like those observed upon first implementation. One limitation of the system is that answers are restricted to numbers or text. Numerical answers are accepted within a defined range. To better accommodate engineering applications, answers are generated outside of the ELMS program and imported into the system. The latter allows for the use of professional engineering software or mathematical modeling software to be used to generate solutions based on a randomly generated set of parameters. Students are given a unique password to access their individual problem sets. The answers for each student are subject to their individualized, unique given parameters. When a student uploads their answers, the system checks for their understanding by allotting them a correct or incorrect response. The number of attempts for each problem is determined by the instructor depending on the complexity of the problem. Students may be given 10 attempts to solve a problem with 20 steps and may use those attempts as they wish to check their answers along the way. If they are confident about a step in the problem, they may continue to the next step without using up one of their attempts. This method of giving limited feedback helps the students to assess competence, develop self-confidence at each step of the problem, and get helpful feedback when needed.

\section{Introduction of the New ELMS to Engineering Materials}

The new ELMS proved to be useful for additional courses apart from thermodynamics. Our engineering materials course is one of the most challenging courses in our curriculum. As such, the class is presented as a flipped course with YouTube video lectures at home and challenges in the classroom. The curriculum for homework included a companion textbook LMS which proved to be effective, but inefficient. The system from the company continued to cut-off in the middle of important assignments. Students grew frustrated in having to re-take the re-assigned homework because of blackouts or wrongly-evaluated questions by the textbook system. Instructor frustration also grew having to alter grades on an individual basis providing no spare time to grade challenges presented in class. Student feedback for the class primarily discussed the expense, which was over one-hundred dollars, for a system that was inaccessible to both the instructor and students.

The engineering materials instructors hesitated to develop a homework system incorporated in blackboard because the use of variables was limited to numeric parameters. For engineering materials, questions needed to reference various material properties and even various elements from the periodic table to generate problems. The MELearn ELMS provided a method for managing such information that can allow questions to vary from student to student by varying chemical information as well as various material properties. As such, the Mechanical Engineering Learn (MELearn) ELMS was utilized to provide a multitude of questions involving various engineering material concepts. The diversity of the homework system allowed images such as phase diagrams to be added to individualized problems for students as seen in Figure 2 


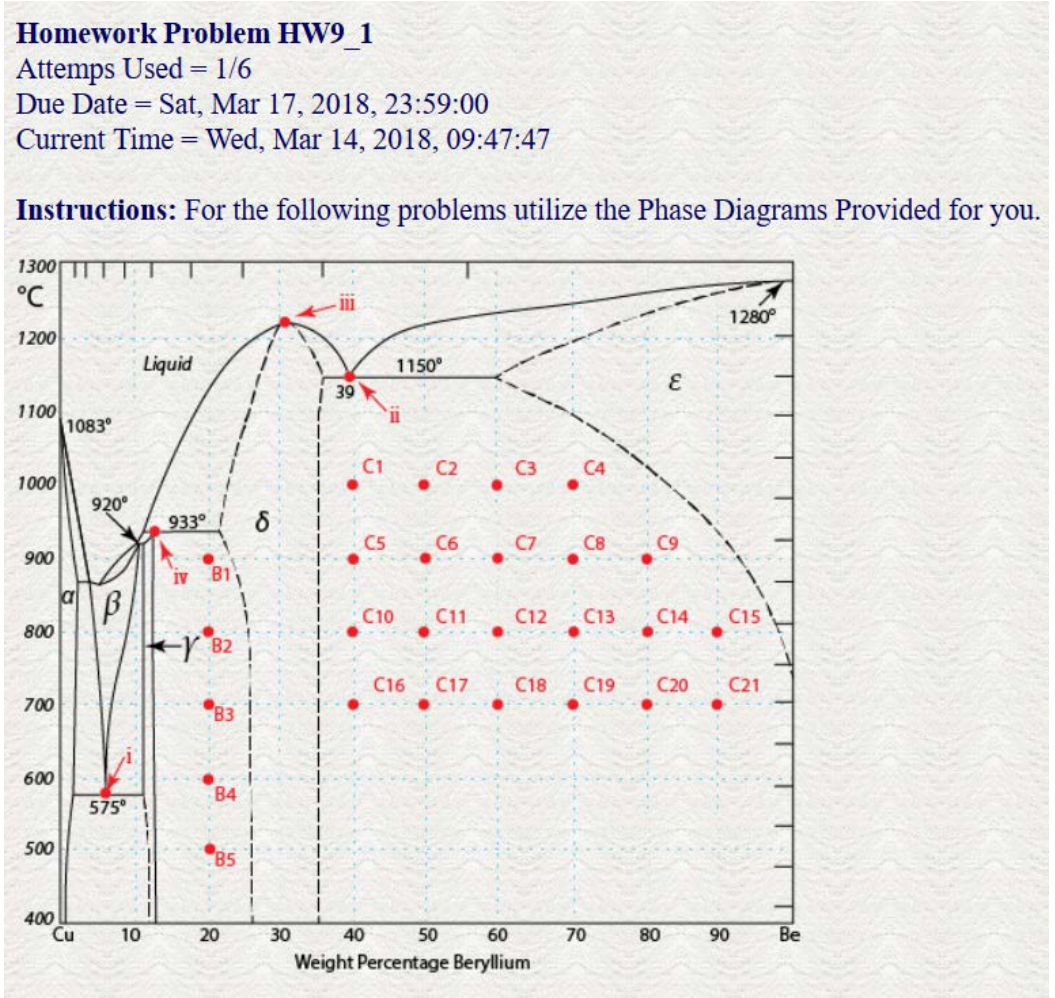

Figure 2: Phase Diagram Problem Image

Additionally, multi-step diffusion problems proved to show the most promise. Because students were unhindered by a system that kept shutting down, they were more engaged in learning the material concepts. The system was implemented in Spring 2017. The results on grade averages over the last two years of instruction are displayed in Table 1 and Figure 3. Over the last year, we have seen some improvement because of the application of the new MELearn ELMS. There is significant improvement on homework grade averages, but the course as a whole has seen an increase in grades because of the interventions provided by this new ELMS.

The two years of data presented are two sections of Spring and Fall of 2016 and 2017 taught by the same instructor. These are four sections consisting of 123 students for 2016 and 119 students for 2017. No student drops were counted as part of the mean grade listed.

Table 3: Statistical Metrics for Data Collected

\begin{tabular}{|c|c|c|c|c|c|}
\hline Statistical Metric & Exam 1 & Exam 2 & Exam 3 & Final & Homework \\
\hline Standard Deviation 2016 & 15.86 & 16.35 & 15.81 & 16.98 & 28.07 \\
\hline Standard Deviation 2017 & 15.76 & 16.42 & 19.32 & 18.24 & 25.75 \\
\hline $\begin{array}{c}\text { T-Test Variance Between } \\
\text { Data Set in 2016-2017 }\end{array}$ & 0.99 & 0.54 & 0.45 & 0.66 & 0.45 \\
\hline
\end{tabular}




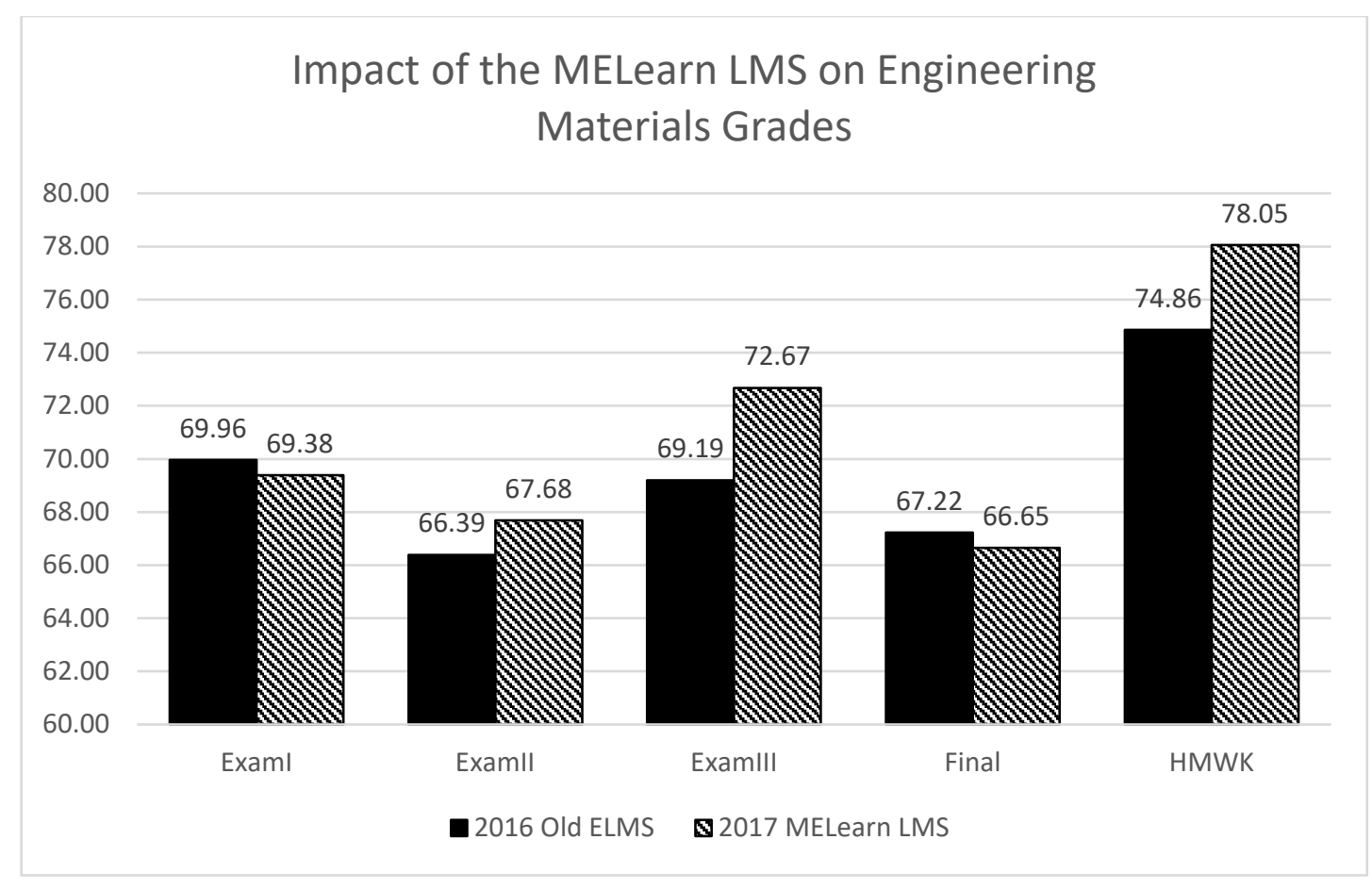

Figure 4: Examination Grades and Homework Grades for the Last Two Years

The advantages of the ELMS for Engineering Materials is very similar to those seen in the thermodynamics course. Students are accountable for their individualized work as it proved to be rather difficult to take advantage of the system since it considers too many variables for each problem. Knowing a formula is not enough for most of the problems presented in engineering materials. Processes must be evaluated using various graphs, diagrams, and tables. As such, we are able to evaluate every part of the process using multi-step problems for each student, not limiting the parameters to one or two, but rather a table of materials and their properties.

\section{Using the new ELMS to Build Familiarity and Confidence with Fundamental Concepts}

The most recent addition to the developed MELearn ELMS for Thermodynamics II is the addition of the ability to enter equations as answers and to automatically, fairly, and accurately assess the validity of submitted answers. The need for such a feature arose out of the unexpected result on an exam question that deviated slightly from those presented in class, the text, and the homework. The Otto power cycle is typically covered in Thermodynamics II in some detail using the cold airstandard method. There are examples of the Otto cycle in the text, example problems done in class, many videos online including the primary author's course website, and several problems given as homework all to reinforce this fundamental cycle. The cycle consists of four simple processes that when evaluated together yield a simple equation for efficiency. The derivation in the text is shown to students in class and is given as a homework assignment turned-in on paper and graded manually. Students were informed that they would be asked to derive the expression for efficiency for a new cycle on the upcoming exam. To test that students understood the process for determining efficiency rather than simply memorizing the solution, the first process was changed from isentropic to isothermal compression, as shown in Figure 4. The other three processes were 
unchanged. Not one student was able to derive the equation for the thermal efficiency ( $\eta$ ). Furthermore, about one third of the students could not determine the temperature at State 2 even though they understood that the process from State 1 to State 2 was isothermal (constant temperature). It became evident that students needed to be challenged to understand beyond having just different numbers with the same equations. They needed to have their own unique set of problems with unique equations, albeit based on other fundamental engineering equations.

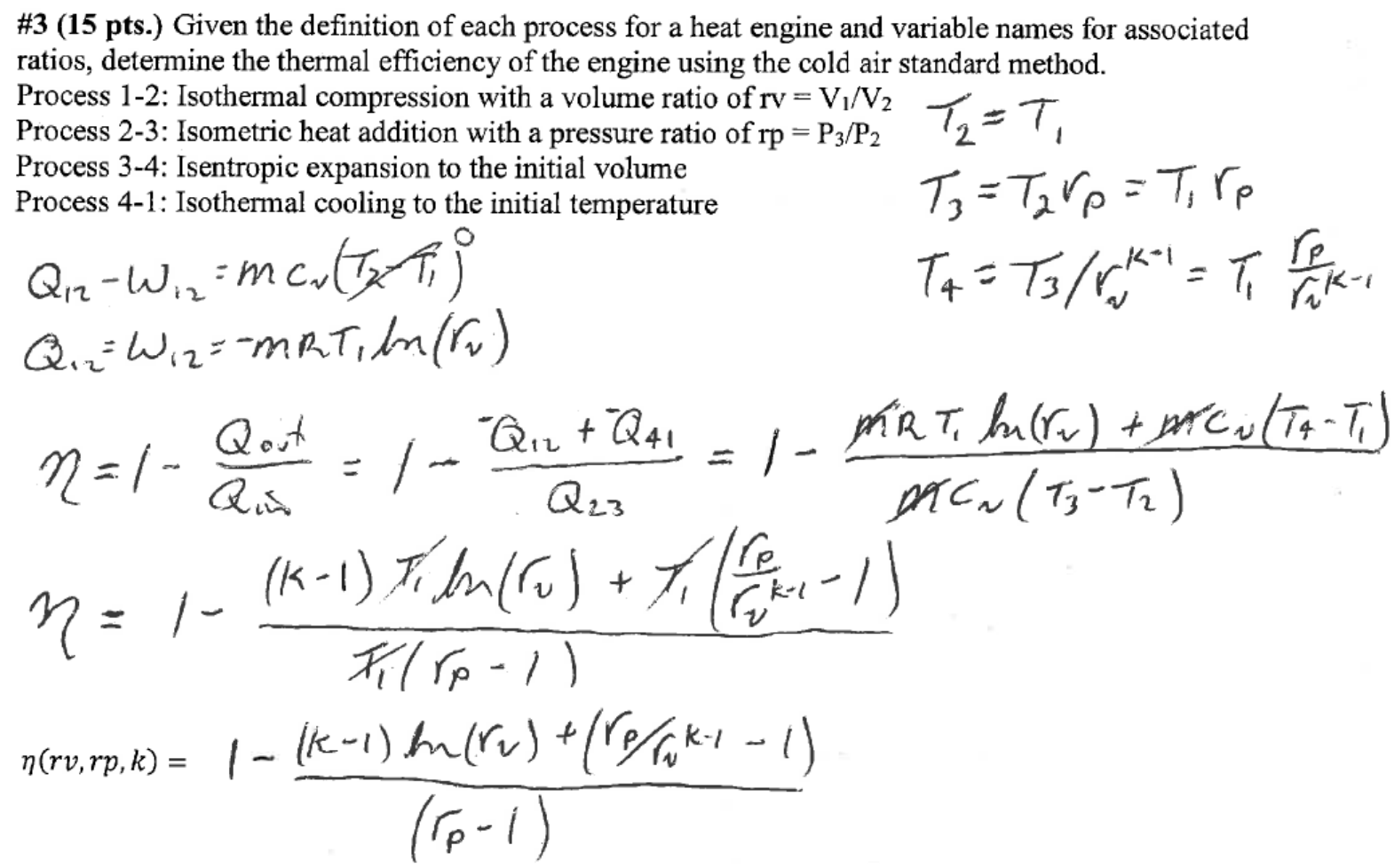

Figure 4: New Student Cycle Problem Given on Exam

A test problem was developed for the new ELMS equation feature to address this power cycle understanding deficiency. The student cycle problem, shown in Figure 5, is a unique set of processes that form a new unnamed cycle. Each student must derive the equation for efficiency for this new cycle and other equations that describe properties and process variables such as work and heat transfer for each step. The allowed variables for each equation are listed between parenthesis after the dependent variable, for example T3(T1, k, rv23) $=\mathrm{T} 1(1 / \mathrm{rv} 23)^{\wedge}(\mathrm{k}-1)$. Students enter their answers as formulas that are then parsed by the program and evaluated. The developed program is able to correctly interpret any form or variation (in the case of multiple solutions) of the equation including implied multiplication as shown in Part $\mathrm{C}$ and $\mathrm{E}$ of Figure 5. The program uses MathML to display a formatted version of the entered formula that is easier to read and debug.

A possible benefit of using a more abstract approach of working with equations to solve new problems rather than with numbers is that students may begin to see problems as a system of equations that define a problem. The approach gives students the opportunity to see the similarity between all of the power cycle problems. A student who can correctly solve this new homework power cycle problem should be able to solve any power cycle problem (i.e. Carnot, Brayton, Diesel, Dual, Stirling, etc.). Based on initial feedback from students and an analysis of their graded work such a benefit may have been achieved. 
The homework problem shown in Figure 5 was introduced to students after the midterm exam. All students were exposed to lectures that emphasized an abstract approach to solving heat engine problems and were assigned homework to do derivations of basic cycles. However, a subset of the class used the new homework assessment tool (shown in Figure 5) for deriving a new power cycle problem that was unique for each student. The treatment shown in Figure 6 is the homework assessment tool. The experimental group is the subset of 33 students who received the treatment, and the control group of 54 students who did not receive the treatment. The groups were voluntary rather than randomly assigned. Although there was a small difference in means between the control group and the experimental group before the treatment, there was a much greater difference in means after the treatment, as demonstrated in Figure 6 . The difference in means for a problem related to the treatment was $26.8 \%$ and for all final exam questions was $14.8 \%$. The pooled standard deviations for those two assessments were $23.9 \%$ and $15.8 \%$, respectively. Adjusting for the initial difference in means between the two groups gives an effect size of 0.82 for the related problem and 0.48 for the final exam. The significant effect size for the related problem would suggest that students who do a unique derivation of a power cycle problem and given feedback in the process are more likely to understand a new cycle. The effect size for the final exam seems to also indicate that the homework assessment had a positive impact on the course in general. This is not surprising as the group of fundamental equations used in the treatment problem were used in many other systems studied throughout the course.

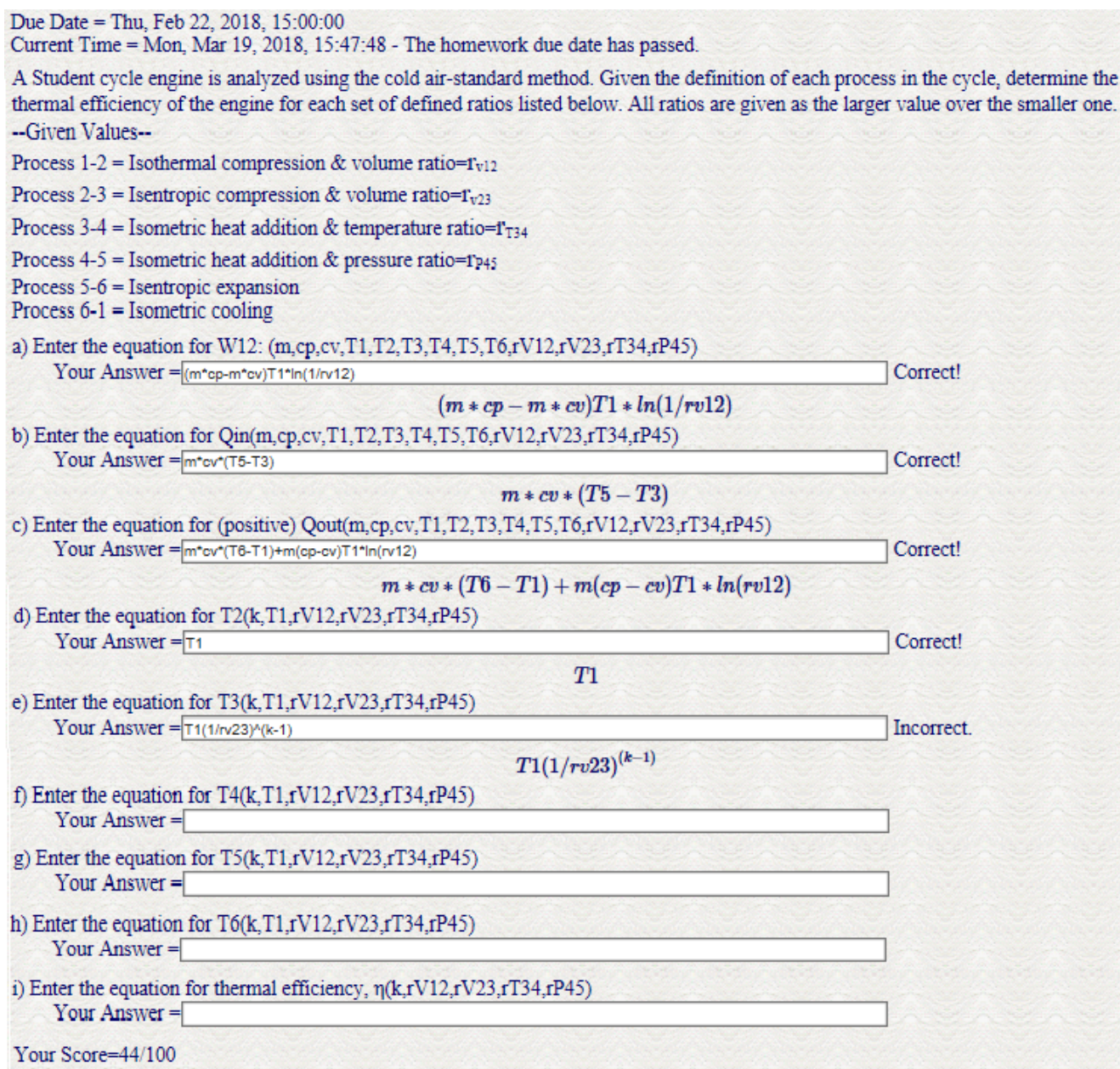

Figure 5: Student Cycle Problem Delivered on New ELMS System 


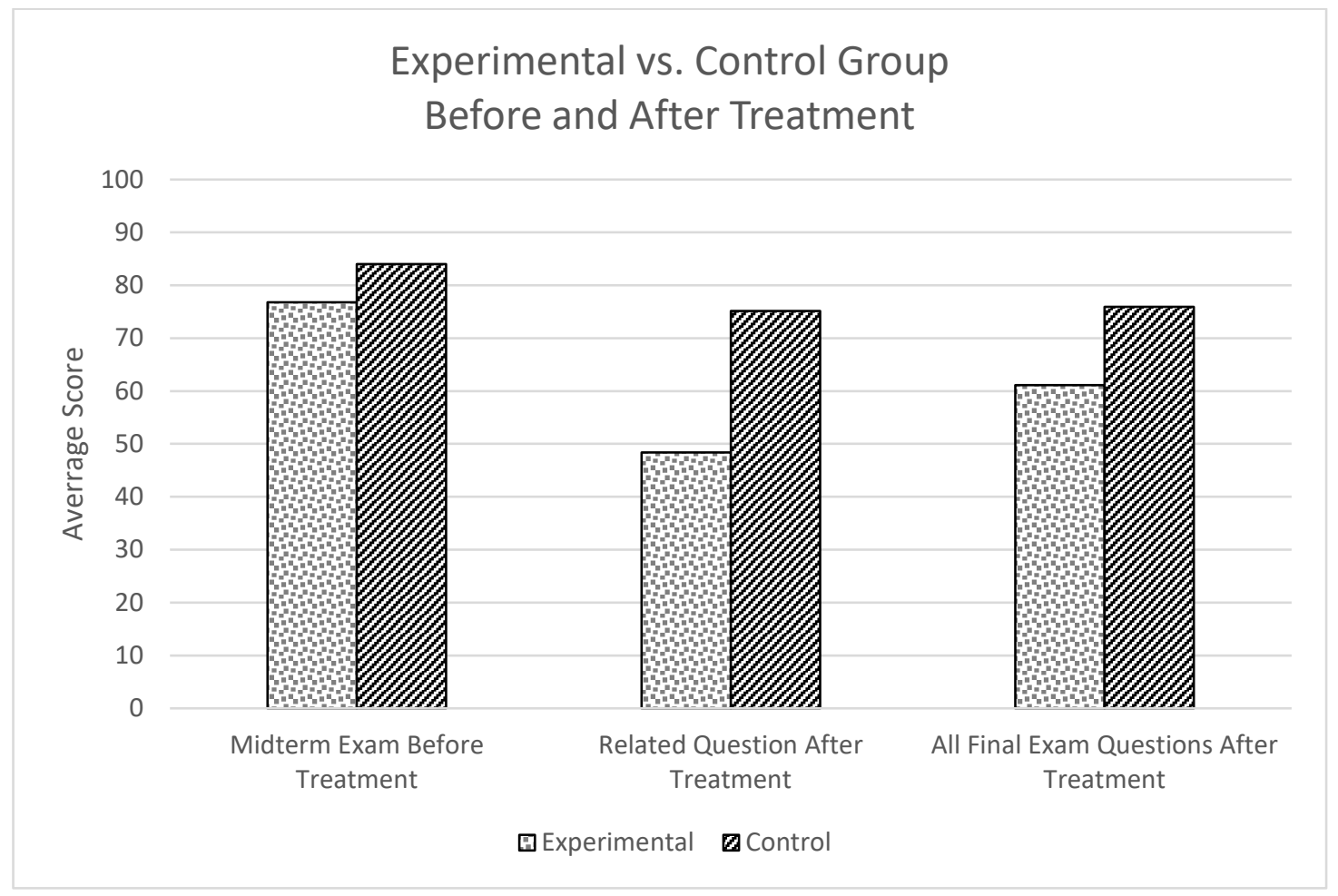

Figure 6: Impact of Student Cycle Problem on Student Learning

\section{Conclusions}

An Electronic Learning Management System (ELMS) platform for the delivery and management of homework problems can be an effective tool in providing formative assessment and feedback to students. Current systems can readily be used for engineering homework problems, but many systems were not designed to specifically meet the needs of more advanced engineering courses. The MELearn ELMS developed by the author attempts to address some of these deficiencies in a way that improves student learning. The system delivers unique problems to each student and provides feedback throughout each problem when needed. The system was designed to encourage individual student work and self-assessment throughout the process. Outside access to the MELearn ELMS is available on a limited basis through the MELearn web site [6]. Using the MELearn ELMS, a marked improvement in student learning and mastery of the fundamental concepts, as measured by exam scores, has been documented for three engineering courses. Most recently, a new feature was added to the system that allows students to enter appropriate equations as answers. The problems were designed to encourage student familiarity with identifying appropriate equations and using a system of equations to solve for various dependent variables, an example being, deriving an equation for thermal efficiency of complex systems. 


\section{References}

[1] R. J. Roselli, and S. P. Brophy, "Experiences with Formative Assessment in Engineering Classrooms,” Journal of Engineering Education, vol 95, pp. 325-333. 2006

[2] J.W. Gikandi, D. Morrow, N.E. Davis, "Online formative assessment in higher education: A review of the literature,” Computers \& Education, vol. 57-4, pp.2333-2351, 2011.

[3] E. Dahlstrom, D. Brooks, and J. Bichsel, “The Current Ecosystem of Learning Management Systems in Higher Education: Student, Faculty, and IT Perspectives,” Research report. Louisville, CO: ECAR, September 2014. Available from http://www.educause.edu/ecar.

[4] ELMS Systems R. Desai, V. Ajay, K. Kumar and Sumangali, "OSLMS: Open source softwares to E Learning - a comparative study," 2015 International Conference on Control, Instrumentation, Communication and Computational Technologies (ICCICCT), Kumaracoil, 2015, pp. 33-37.

[5] A. Arguelles, C. Tarawneh, Y. Park, S. W. Crown, "Developing positive study habits through course recitation,” Journal of Applications and Practices in Engineering Education, vol. 3, no. 1, pp. 1-12, 2012.

[6] https://melearn.utrgv.edu/ELMS 